\title{
Isolation and Characterization of Aquaspirillum fasciculus sp. nov., a Rod-shaped, Nitrogen-Fixing Bacterium Having Unusual Flagella
}

\author{
W. J. STRENGTH, BILQUIS ISANI, D. M. LINN, ${ }^{1}$ F. D. WILLIAMS, GAIL E. VANDERMOLEN ${ }^{2}$
} BARBARA E. LAUGHON, ${ }^{1}$ AND N. R. KRIEG

Department of Biology, Virginia Polytechnic Institute and State University, Blacksburg, Virginia 24061; and Departments of Bacteriology and Botany, Iowa State University, Ames, Iowa 50010

In 1971, Strength and Krieg reported the isolation of a gram-negative freshwater rod which exhibited bipolar flagellar fascicles clearly visible by dark-field microscopy. The flagellar fascicles exhibited helical wave propagation, basal bending, and an ability to coil up like springs. Despite the flagellar activity, the cells were apparently unable to swim freely. Such organisms appeared to be similar morphologically to an organism previously described by Houwink in 1953 and Jarosch in 1969. The present report describes a reliable isolation method for such organisms based on the use of L-proline and semisolid agar. Upon isolation, the organisms grew in flocs, from which a highly viscous matrix could be separated by high-speed centrifugation. After many transfers, the growth gradually became homogeneous and turbid, and the viscous substance could no longer be demonstrated. Under certain conditions of growth, steady straight-line motility could be observed and photographed within viscous flocs. Straight-line, free-swimming motility occurred in viscous suspensions of cells prepared by homogenization of flocs. In 8- to 12-h-old cultures in the nonviscous homogeneous condition, some cells could swim slowly in irregular, circular paths; other could move about on surfaces. When the viscosity of the medium was increased, nearly every cell could swim freely and steadily in straight paths. A viscosity of 200 centipoise was optimal for strain XI, whereas 10 centipoise was optimal for strains X and XII. These results suggest that the organisms may be highly adapted to life within viscous flocs. The organism exhibited nitrogenase activity when tested by methods developed by Döbereiner and her colleagues for "Spirillum" lipoferum; Aquaspirillum peregrinum also was found to possess nitrogenase activity. Investigation of the physiology and deoxyribonucleic acid base composition of strains X, XI, and XII has indicated that even though the organisms are straight rods, they are probably members of the genus Aquaspirillum. Important taxonomic considerations include: coccoid body or "microcyst" formation, possession of a "polar membrane" similar to that occurring in certain spirilla, bipolar tufts of flagella, a strictly respiratory metabolism, inability to attack carbohydrates, positive catalase and oxidase reactions, and a deoxyribonucleic acid base composition of 62 to $65 \mathrm{~mol} \%$ guanine plus cytosine. The organisms were assigned to a new species, Aquaspirillum fasciculus, and the type strain was deposited with the American Type Culture Collection under the number 27740.

In 1953, Houwink (11) described a "rod-like" bacterium which exhibited a "floundering" rather than a swimming type of motility. In resting specimens, both bipolar flagellar fascicles had the form of a coiled spring. The cells seldom moved more than a cell length, but in

\footnotetext{
${ }^{1}$ Present address: Anaerobe Laboratory, Virginia Polytechnic Institute and State University, Blacksburg, Va. 24061.

2 Present address: Department of Biological Sciences, Florida Technological University, Orlando, Fla. 32816.
}

some preparations cells were observed to move in a straight line for about $100 \mu \mathrm{m}$. During locomotion, the apical fascicle wound around the bacterium in wide curves, and the distal fascicle extended behind the cell. A reorientation of the fascicles occurred when the cells reversed direction. Houwink regarded the organisms as probably belonging to the genus Spirillum. In 1969 , a rod-shaped bacterium from mud was described by Jarosch (13). This organism also possessed bipolar flagellar fascicles 
and could not swim freely, but it could move about on surfaces. When moving in this manner, the front fascicle appeared to be coiled around the cell while the rear fascicle was extended behind the cell. The flagellar orientation was reversed when the cells reversed direction. When extended, the fascicles exhibited helical wave propagation from base to tip. Jarosch's organism was not isolated. In 1971, Strength and Krieg (30) isolated a gram-negative, floc-forming, freshwater rod which exhibited bipolar flagellar fascicles. The fascicles were easily seen by dark-field microscopy, were intensely active, and exhibited three modes of behavior as recorded by cinephotomicrography. These modes are summarized diagramatically in Fig. 1. Despite the activity of the fascicles, the cells appeared to be unable to swim; instead they "floundered" about ineffectually. Electron micrographs of the coiled and twisted flagella closely resembled the micrographs presented by
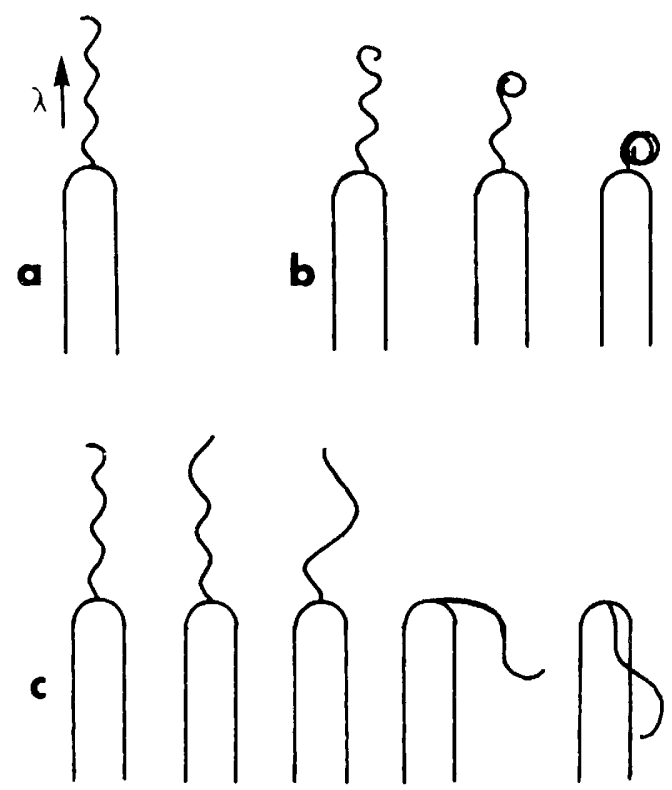

FIG. 1. Diagram of flagellar behavior observed by Strength and Krieg (30) for free cells located near the edge of a floc. Despite the flagellar activity, the cells were not capable of swimming freely. The "flagellum" is a fascicle of about 10 to 12 individual flagella acting in concert, each flagellum having a separate insertion in the cell wall. (a) Generation of helical waves along an extended fascicle from base to tip. (b) Spring-like coiling of fascicle into a loop. (c) Change of wavelength followed by bending of fascicle at the base. The sequences illustrated in (b) and (c) are reversible. Although only one polar fascicle is illustrated, the organisms possessed a fascicle at each pole; the behavior at one pole had no relation to the behavior at the opposite pole.
Houwink. It seems likely that the various organisms described by all of the preceding authors are very similar, possibly even identical, to one another. Such unusual bacteria deserve additional study, and the present report concerns their isolation, characterization, and taxonomy. The ability of the bacteria to swim freely in highly viscous media is also described.

\section{MATERIALS AND METHODS}

Previous isolation methods. Strains $\mathrm{X}$ and XI were derived from hay infusions prepared with pond water at Virginia Polytechnic Institute and State University (VPI\&SU), Blacksburg, Va. Strain X was isolated in July 1967, from an enrichment culture of the surface scum of a hay infusion. Enrichment was accomplished with Pringsheim soil medium (25), and this was followed by dilution plating in a semisolid peptone-succinate salts medium (12). The organisms grew in flocs which were subsequently streaked on a solid peptone-succinate salts medium. Only one colony proved to be pure by microscope examination, and many additional isolation attempts using this method have proven unsuccessful.

An additional strain was isolated in August 1968 by the decreased oxygen method described by Strength and Krieg (30). This strain was maintained by serial transfer until December 1968, when it died for reasons which were not then apparent. Subsequent study of other strains have indicated that coccoid body formation similar to that seen in various spirilla (12) occurs within 2 to 3 days; these bodies appeared to be degenerative forms, and their formation probably accounted for the loss of the above-mentioned strain. The decreased-oxygen method of isolation has proven to be unreliable for isolation of additional strains.

Strain XI was isolated in August 1969 by the cellulose-powder method previously described (30). Again, this method has proven to be unreliable.

Media. Peptone-fumarate salts medium (PFS) was described previously (30) and was used in liquid, semisolid $(0.15 \%$ agar), or solid (1.5\% agar) form. Proline-salts (PR) medium has the following composition (\%): L-proline, 0.05; $\mathrm{K}_{2} \mathrm{HPO}_{4}, 0.045$; $\mathrm{MgSO}_{4} \cdot 7 \mathrm{H}_{2} \mathrm{O}, 0.025 ; \quad \mathrm{MnSO}_{4} \cdot \mathrm{H}_{2} \mathrm{O}, \quad 0.0001 ;$ and $\mathrm{FeCl}_{3} \cdot 6 \mathrm{H}_{2} \mathrm{O}, 0.0001$. The $\mathrm{pH}$ was adjusted to 7.0 with $\mathrm{KOH}$. Diluent for washing cells for nutritional studies had the composition of double-strength PR broth except for omission of proline. The basal medium (BM) for determination of compounds which could serve as sole carbon sources had the composition of PFS medium except for omission of peptone and fumaric acid, with decrease of $\left(\mathrm{NH}_{4}\right)_{2} \mathrm{SO}_{4}$ to $0.066 \%$ and addition of $0.15 \%$ purified agar (BBL). For determination of sole nitrogen sources, fumaric acid $(0.2 \%)$ was added to the $\mathrm{BM}$ and the $\left(\mathrm{NH}_{4}\right)_{2} \mathrm{SO}_{4}$ was omitted. For compounds which could serve as sources of both carbon and nitrogen, neither fumaric acid nor $\left(\mathrm{NH}_{4}\right)_{2} \mathrm{SO}_{4}$ was supplied. All compounds tested as carbon or nitrogen sources were provided on an equal carbon basis relative to $0.2 \%$ fumaric 
acid or $0.066 \%\left(\mathrm{NH}_{4}\right)_{2} \mathrm{SO}_{4}$, respectively, and were sterilized by filtration.

Inocula. The second of two, serial 18-h-old transfers in PFS semisolid medium was used as the source of inoculum for physiological tests. For tests employing semisolid media, $0.05 \mathrm{ml}$ (removed after dispersing the surface growth throughout the tube) was used as inoculum. A 5-mm loopful of the suspension was used to streak solidified test media. The inoculum for testing sole carbon and nitrogen sources was prepared by inoculating PFS agar slants from the semisolid agar culture; after $18 \mathrm{~h}$, the cells were washed off the slants with sterile diluent (see above) and were then washed twice by centrifugation. Clumps were dispersed by gentle shaking, and the tubes were allowed to stand for 5 min to permit any remaining clumps to settle out. The resulting supernatant was diluted to a turbidity of 50 Klett units, using a colorimeter (Klett Manufacturing Co., New York, N.Y.), 16-mm cuvettes, and a blue $(420 \mathrm{~nm})$ filter. One-tenth milliliter of a 1:10 dilution of this suspension was used as inoculum for the test media. The latter were contained in 10 -ml volumes in tubes ( 16 by $150 \mathrm{~mm}$ ) with loosened screw caps.

Measurement of growth responses to sole carbon and nitrogen sources. Growth responses were estimated turbidimetrically at $36 \mathrm{~h}$, using $16-\mathrm{mm} \mathrm{cu}-$ vettes and a blue $(420 \mathrm{~nm})$ filter. Since growth occurred only at the surface of the semisolid test media, cultures were gently inverted six times to obtain an even distribution of cells. A positive growth response was defined as the production of at least 10 Klett units of turbidity for at least six serial transfers in the test media.

Physiological tests. Physiological tests were performed as described previously by Hylemon et al. (12) for spirilla, with the following exceptions. PFS medium, in liquid, semisolid, or solid form, was used instead of succinate-based media (see Table 3). Tributyrin hydrolysis was tested by incubating plates of PFS agar containing $1.0 \%$ tributyrin for up to 14 days and examining for zones of clearing. Catalase production was determined on PFS agar slants incubated for $24 \mathrm{~h}$. Acidic reactions from sugars were determined on a modified PFS semisolid medium: peptone was decreased to $0.2 \%$, fumaric acid was omitted, and $0.0003 \%$ bromothymol blue was used as an indicator. Antibiotic susceptibilities were determined by noting the presence of zones of inhibition at $24 \mathrm{~h}$ on the seeded surfaces of PFS agar plates containing paper disks impregnated with antibiotics at the levels indicated in Table 3 . Intracellular granules, previously photographed by Strength and Krieg (30), were extracted with hypochlorite, and the polymer was identified by the method of Law and Slepecky (19). Oxygen uptake was estimated by constant-volume manometry using cell suspensions prepared from 12-h-old cultures. The reaction vessels contained the following components (final concentrations): $0.01 \mathrm{M}$ phosphate buffer ( $\mathrm{pH} 7.0$ ), washed cells (116 Klett units turbidity using a blue $[420 \mathrm{~nm}$ ] filter and $16-\mathrm{mm}$ cuvettes), and substrate (supplied on an equal carbon basis relative to $5.7 \times 10^{3} \mathrm{M}$ fumaric acid). Deoxyribonu- cleic acid (DNA) base compositions were determined as previously described (12). To test the possibility that the organisms might be capable of nitrogen fixation, the acetylene reduction method described by Postgate (22) was used. Homogeneous cultures (i.e., cultures which after prolonged transfer had lost their initial ability to form cell flocs) of strains $\mathrm{X}, \mathrm{XI}$, and XII were cultured for $12 \mathrm{~h}$ at $30 \mathrm{C}$ in PFS broth for three serial transfers. The cells from the last transfer were washed twice with sterile distilled water and resuspended to a turbidity of 30 Klett units (using $16-\mathrm{mm}$ cuvettes and a blue $[420 \mathrm{~nm}]$ filter). In the case of strain XII, a turbidity of 150 Klett units was used, as this strain was found to grow more slowly than the others in the succeeding steps. Each strain was inoculated $(0.05 \mathrm{ml})$ into 3.0 $\mathrm{ml}$ of test media contained in tubes ( 16 by $125 \mathrm{~mm}$ ) having loosely fitting plastic closures. The test medium employed was that described by von Bülow and Döbereiner (33), with the omission of sodium malate and the addition of $0.005 \%$ yeast extract. Four modifications were used: (i) liquid rather than semisolid medium; (ii) liquid medium $+0.1 \%$ $\left(\mathrm{NH}_{4}\right)_{2} \mathrm{SO}_{4}$; (iii) semisolid medium $(0.175 \%$ agar); and (iv) semisolid medium $+0.1 \%\left(\mathrm{NH}_{4}\right)_{2} \mathrm{SO}_{4}$. Semisolid media were melted and inoculated at $45 \mathrm{C}$ to give a uniform distribution of cells. Cultures were incubated at $30 \mathrm{C}$ for 3 and 5 days; they were then sealed with rubber vaccine-bottle stoppers. A 2-ml volume of acetylene (generated from $\mathrm{CaC}_{2}$ ) was then injected, and the tubes were tested for ethylene production after $1 \mathrm{~h}$. A Beckman GC-4 gas chromatograph (Beckman Instruments, Fullerton, Calif.) equipped with 6 - $\mathrm{ft}$ by 0.25 -inch (approximately 30.5 by $0.6-\mathrm{cm}$ ) glass columns (containing Porapak $\mathrm{T}$ [Waters Associates, Inc., Framingham, Mass.|) and flame ionization detector was used. An oven temperature of $60 \mathrm{C}$ and carrier gas (helium) flow rate of 85 $\mathrm{ml} / \mathrm{min}$ were used. Sterile medium controls were included. As an adjunct to the study, Aquaspirillum peregrinum ATCC 15387 was also tested in the same manner as strains $\mathrm{X}$ and $\mathrm{XI}$.

Motility-track photomicrographs. For estimation of the proportion of motile cells and their velocity, in relation to the viscosity of the suspending medium, the time-exposure, motility-track method of Vaituzis and Doetsch (32) was used. Only cultures exhibiting homogeneous growth (see Results) were employed. Strains were cultured for four serial transfers in $100 \mathrm{ml}$ of PFS broth (contained in 250 $\mathrm{ml}$, cotton-stoppered Erlenmeyer flasks) using 0.1 $\mathrm{ml}$ of each previous culture as inoculum for the next. Each transfer was incubated at $30 \mathrm{C}$ on a reciprocating shaker (70 oscillations per min). The final culture in each series was used for preparation of motility-track photomicrographs at 8,12 , and $24 \mathrm{~h}$ of incubation. A $1-\mathrm{ml}$ volume culture was combined with $1.0 \mathrm{ml}$ of various concentrations of methycellulose ("400 cp"; Fisher Scientific Co., Silver Spring, Md.), and pure oxygen was bubbled through the rnixture for 1 min to increase motility to its maximum. Wet mounts were prepared by placing a circular no. 1 cover slip over a small drop and allowing the weight of the slip to flatten the drop to the edges. Pressure was not employed because it would cause 
extensive and prolonged streaming at the higher viscosities. Wet mounts were sealed with melted petrolatum and were immediately photographed for $15 \mathrm{~s}$ at room temperature $(25 \mathrm{C})$ with a Leitz Ortholux microscope equipped with a $25 \times$ objective, $10 \times$ eyepiece, dark-field condenser, 150-W xenon lamp, and $35-\mathrm{mm}$ Leica camera. Films (Kodak Plus-X Pan) were developed for $5 \mathrm{~min}$ at $21 \mathrm{C}$ in Kodak DK$60 \mathrm{~A}$ developer. Two photomicrographs were analyzed for each mixture of culture and methylcellulose. The proportion of motile cells was determined from the photographs, and, after subtracting the average length of a cell from the length of each motility track, the average velocity for the motile cells was calculated. Viscosities of the methylcellulose mixtures were estimated with an Ostwald viscosimeter at $25 \mathrm{C}$, using glycerol as a reference.

Electron microscopy. Cells of strain X and XII were harvested from PFS broth and fixed at room temperature using the method of Kellenberger et al. (17) as reported by Kay (15). The cells were dehydrated through an ethanol series, infiltrated with propylene oxide, and embedded in Epon 812. Sections $60-\mathrm{nm}$ thick were cut with a diamond knife and were stained with both uranyl acetate (29) and lead citrate (23). Sections were photographed with a $\mathrm{Hi}$ tachi HY-11C electron microscope operated at $50 \mathrm{kV}$.

\section{RESULTS}

Development of a reliable isolation method. Organisms resembling the cells of strains $X$ and XI generally reached maximal numbers in the surface scum of pond water-hay infusions in 3 days when incubated at $30 \mathrm{C}$ in shallow pans. Some enrichment could be achieved by subsequent cultivation of the scum in Pringsheim soil medium (25), and again the organisms were found mainly in the surface pellicle. Even with this enrichment, the organisms were vastly outnumbered by contaminants. Nutritional studies of the previously isolated strains $\mathrm{X}$ and XI indicated that L-proline could be used as a sole source of both carbon and nitrogen (see below), and the possibility that many of the contaminants might not be able to use this amino acid eventually led to the development of a thoroughly reliable isolation method, as follows. (i) A loopful of the surface pellicle from a 4-day-old mixed culture in Pringsheim soil medium was transferred to $10 \mathrm{ml}$ of sterile water. The suspension was shaken vigorously to disperse the cell flocs characteristically formed by the organisms. (ii) Serial dilutions in sterile water were prepared from this suspension. (iii) Each dilution was used to seed plates of melted, cooled PR medium containing $0.75 \%$ agar. (It should be noted that plates of solidified $11.5 \%$ agar] PR medium which were streaked or which were sprayed with an atomizer invariably failed to yield colonies of the organism.) (iv) After $36 \mathrm{~h}$ of incubation at $30 \mathrm{C}$, numerous small (0.1- to 0.4-mm diameter), white, irregularly shaped colonies, as well as other types of colonies, appeared in the agar. The small white colonies could best be seen with a dissecting microscope and could be picked with sterile capillary tubes. (v) Each capillary tube containing a plug of agar with an isolated colony was blown out into a tube containing doublestrength PR medium containing $0.15 \%$ agar. It was advantageous to crush the agar plugs with a glass rod after such transfer.

The use of this method led to the successful isolation of organisms from mixed cultures derived from pond water at Iowa State University. The pond water had been initially enriched with $0.3 \%$ dehydrated nutrient broth, but ordinary methods of isolation were uniformly unsuccessful in obtaining a pure culture. The organisms were easily isolated by the procedure described above, and the strain isolated from the pond water was designated as strain XII in our laboratory. Since that time (July 1971), many other isolates have been obtained in a similar manner by a number of students in our (VPI\&SU) laboratory.

Preservation of isolates. Strains may be maintained by serial transfer at 48 -h intervals in semisolid PFS medium. When incubation is extended beyond this period, cultures often lose viability, possibly because of extensive formation of coccoid bodies. Cultures which become homogeneous in their growth characteristics after many transfers (see below) grow more rapidly and also die more rapidly than flocculent cultures. Isolates may be preserved indefinitely by preparing a dense cell suspension in PFS broth containing 15\% glycerol and freezing the suspension in liquid nitrogen.

Morphological features of strains X, XI, and XII. The dimensions of living cells cultured in PFS broth on a shaking machine were estimated using phase-contrast microscopy (Table 1). Strain XII had slightly greater cell dimensions than the other strains. When cultured for $24 \mathrm{~h}$, cell lengths were greater than those at $8 \mathrm{~h}$, but cell diameters remained essentially constant. Strength and Krieg (30) and Jarosch (13) had previously reported larger cell diameters for the organisms they had observed, but dark-field microscopy, which falsely augments the dimensions, had been employed.

The numerous, large, intracellular granules were found to be rich in poly- $\beta$-hydroxybutyrate.

Coccoid bodies became predominant in 48- to 72-h-old cultures in PFS broth or PFS semisolid medium (Fig. 2). These forms originated as protuberances along the rods and appeared to result from a weakening of the cell wall. Their 
TABLE 1. Dimensions of strains $X, X I$, and $X I I^{a}$

\begin{tabular}{cccccc}
\hline \multirow{2}{*}{ Strain } & $\begin{array}{c}\text { Age of culture } \\
(\mathrm{h})\end{array}$ & \multicolumn{2}{c}{ Cell diam $(\mu \mathrm{m})$} & \multicolumn{2}{c}{ Cell length $(\mu \mathrm{m})$} \\
& & Mean & Range & Mean & Range \\
\hline X & 24 & 0.74 & $0.60-0.94$ & 7.7 & $4.3-14.6$ \\
XI & 8 & 0.78 & $0.52-1.03$ & 20.1 & $6.5-43.0$ \\
& 24 & 0.73 & $0.60-0.90$ & 7.4 & $4.4-17.6$ \\
XII & 8 & 0.79 & $0.60-0.93$ & & $6.2-40.5$ \\
& 24 & 0.91 & $0.82-1.03$ & 6.4 & $3.6-11.0$ \\
\hline
\end{tabular}

"Cells were cultured in cotton-stoppered Erlenmeyer flasks (250-ml capacity) containing $100 \mathrm{ml}$ of PFS broth, incubated at $30 \mathrm{C}$ on a reciprocating ( 70 oscillations per min) water-bath shaker. Dimensions of living cells were measured with a phase-contrast microscope fitted with a calibrated Filar micrometer eyepiece.

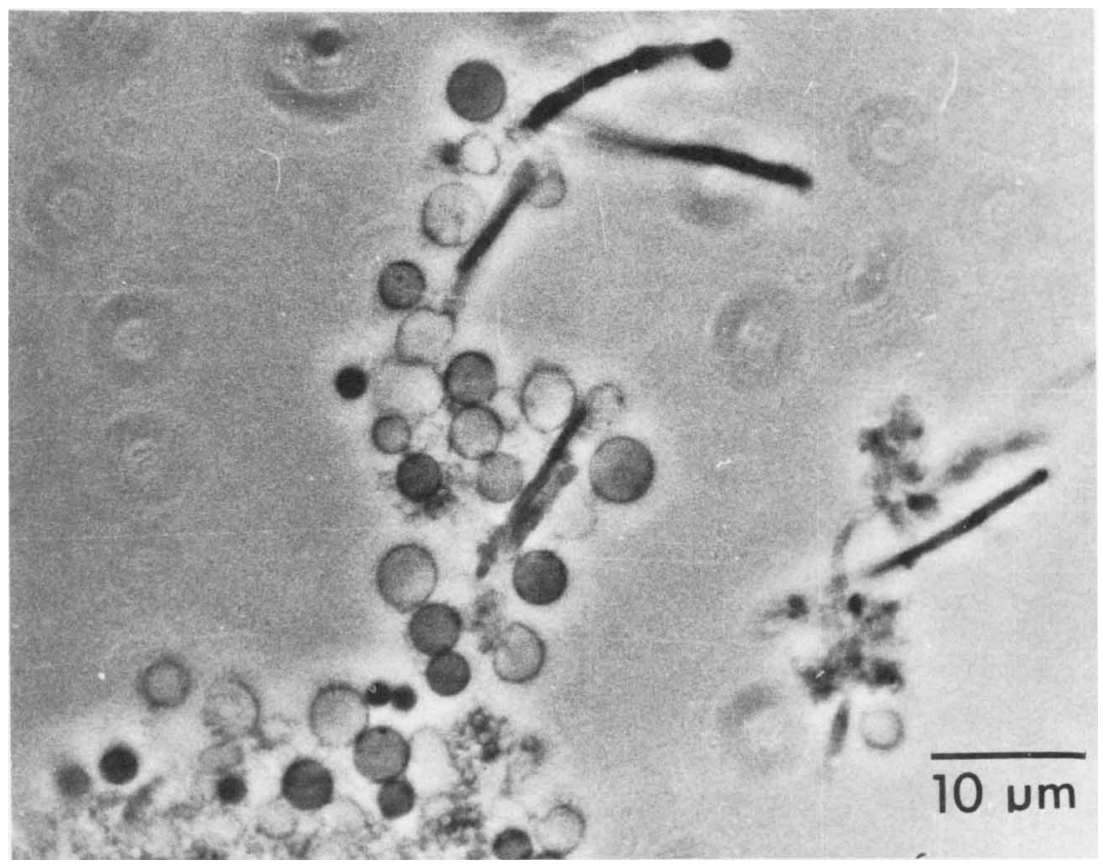

FIG. 2. Coccoid bodies of strain XI in PFS broth cultures incubated at $30 \mathrm{C}$ for $48 \mathrm{~h}$ on a shaking machine. Phase-contrast microscopy.

diameters ranged from 1.3 to $4.2 \mu \mathrm{m}$ by phasecontrast microscopy. Cultures consisting mainly of coccoid bodies were frequently not viable upon transfer to fresh media.

Thin sections of cells of strains X and XII (XI was not examined) revealed the occurrence of an inner, or cytoplasmic, membrane (Fig. 3B) as well as an outer, or wall, membrane characteristic of gram-negative bacteria. Underlying the inner, or cytoplasmic, membrane at the cell poles were segments of a membrane-like structure connected to the cytoplasmic membrane by striations (Fig. 3A). Neither strain revealed similar structures at locations other than the poles of the cells. The segments resembled those of the "polar membrane" described by
Murray and Birch-Andersen (20) for Spirillum serpens and by other authors for various helical bacteria $(9,10,16,24)$.

Changes in cultural characteristics subsequent to isolation. All strains so far isolated have characteristically formed large flocs in PFS broth incubated statically after primary isolation. With incubation on a shaking machine, a single large floc was formed which gradually increased in size during incubation. Such flocs possessed a highly viscous consistency, but the medium itself did not become viscous. The masses of cells could be teased apart on a slide into long strings. Within the strings the bacteria exhibited parallel or endto-end arrangements, but they were not in con- 

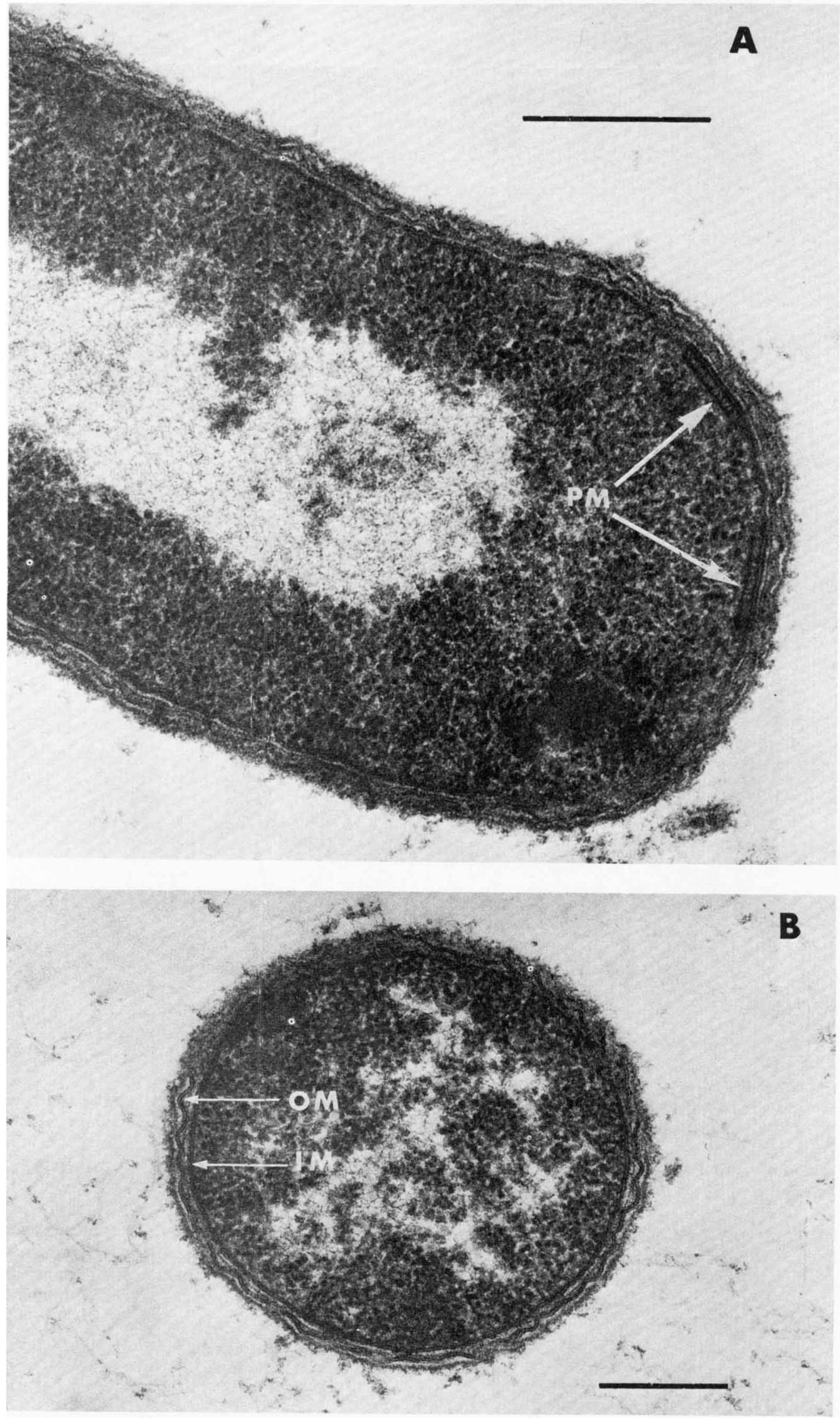
tact with one another and they did not exhibit Brownian motion. Occasionally a string of cells stretched between two clumps would break at the middle, with each half rapidly retracting back into the main mass of cells. These observations suggested the presence of a viscous matrix in which the cells were embedded, but all attempts to demonstrate such a matrix unequivocally by cytological methods (compressed India ink wet mounts, or fluorescent dyes [8]) failed. A crude preparation of the viscous material could be obtained, however, by the following procedure. (i) Cultures were centrifuged at $3,000 \times g$ for $10 \mathrm{~min}$, and the supernatant medium (nonviscous) was discarded. (ii) Subsequent centrifugation of the pellet at $40,000 \times g$ for 30 min yielded a translucent, highly viscous supernatant. Many detached loops of flagellar fascicles were present. (iii) A transparent, highly viscous supernatant was obtained by additional centrifugation at $100,000 \times g$ for $2 \mathrm{~h}$. The chemical composition of the viscous substance has not been determined.

After several serial transfers beyond initial isolation, all isolates gradually but inexorably began to lose their floc-forming ability. A number of smaller flocs appeared instead of the single large floc, and eventually, after 20 to 30 transfers, growth became completely homogeneous and turbid. No viscous material could be obtained from such cultures.

Motility in cell flocs. When wet mounts of flocs were examined by dark-field microscopy, the cells could be seen on rare occasions moving about in relatively straight lines within the flocs. With cultivation in $0.1 \times$ PFS broth for 48 to $72 \mathrm{~h}$, motility within flocs was observed more frequently. Highly viscous flocs from cultures transferred only a few times after initial isolation were more satisfactory than less viscous flocs from cultures beginning to exhibit homogeneous, turbid growth. Within the flocs, the cells were arranged largely in parallel. Nearly all of the cells could be seen moving slowly in straight lines. The motility was not attributable to streaming within the floc, since adjacent cells frequently passed one another or moved in opposite directions. Motion pictures taken of such flocs clearly showed the motility of the cells, but only in sparsely populated areas within the crushed flocs was the clarity sufficient to permit analysis of individual frames (Fig. 4). Because of diffusion of light within the flocs, the polar flagellar fascicles could not be discerned. Individual cells which were external to the flocs, if motile at all, moved only short distances and in an irregular, floundering manner. Occasionally, some of these cells would reenter the flocs and resume a straight-line type of motility.

When flocs cultured in $0.1 \times$ PFS broth were crushed with a glass rod and thoroughly homogenized in a small quantity of distilled water, the resulting suspension became highly viscous. Wet mounts exhibited free-swimming cells moving in relatively straight lines without reversal of direction. The velocity of swimming was slow compared to that of such organisms as Escherichia coli or Pseudomonas aeruginosa. The tailing flagellar fascicle was extended behind the cells and exhibited helical wave propagation from base to tip while the leading fascicle was coiled either into a polar loop (Fig. 1B) or around the cell (Fig. 5).

Motility in the presence of viscous agents. The results cited above suggested that the organisms might be able to swim freely if the viscosity of the medium were to be increased by addition of various agents. Only cultures giving homogeneous, turbid growth were used to test this hypothesis because their cells were free of any preexistent, naturally occurring viscous matter. Among the agents added to cell suspensions were: Ficoll (Pharmacia Fine Chemicals, Piscataway, N.J.; molecular weight $=400,000$ ), polyethylene glycol (molecular weight $=3,000$ to 3,700 ), gum arabic, gum tragacanth, gelatin (Difco), DNA (Difco), and methylcellulose (" 400 cp"). Only the latter three agents were effective. The age of the cultures was important, with the maximal number of motile cells occurring with cultures incubated for 8 to $10 \mathrm{~h}$ in shaken PFS broth at $30 \mathrm{C}$. Also, the bubbling of pure oxygen through the mixture of culture and viscous agent just prior to making wet mounts stimulated motility. With the three effective viscous agents, a similar pattern occurred when cells of strain XI were tested. (i) For each agent, an optimal concentration existed (8\%, $0.75 \%$, and $1.5 \%$ for gelatin, DNA, and methylcellulose, respectively) at which nearly every cell exhibited straight-line swimming without reversal of direction (Fig. 6A). The tailing fascicles were extended behind the cells, with helical waves being propagated from base to tip. The leading fascicle for each cell was not visible, and indeed there was initial doubt as to its existence in these young cells. Suspension of the cells in $10 \%$ polyethylene glycol, although not permitting motility, did cause extension of

FIG. 3. (A) Longitudinal section through a cell from strain XII showing segments of the "polar membrane" (PM). Marker $=0.25 \mu \mathrm{m}$. (B) Cross-section of a cell from strain XII showing outer or wall membrane (OM) and inner or cytoplasmic membrane (IM). Marker $=0.25 \mu \mathrm{m}$. 

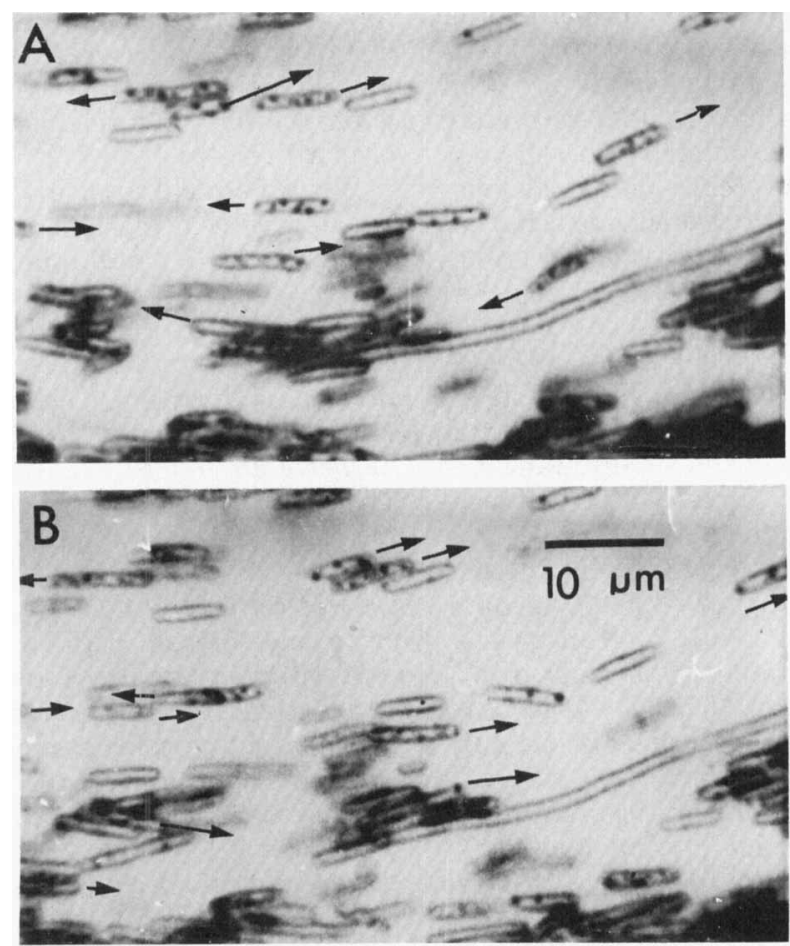

FIG. 4. Negative prints of two frames taken from a dark-field cinephotomicrography sequence showing a sparsely populated portion within a cell floc of strain X. Frame B was taken $1.7 \mathrm{~s}$ after frame A. The arrows indicate the straight-line directions being taken by various motile cells. The cell flocs contain a highly viscous matrix.

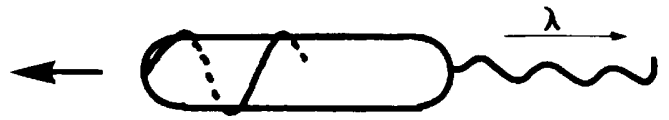

FIG. 5. Diagrammatic illustration of the orientation of the flagellar fascicles of free-swimming cells observed when cell flocs cultured in $0.1 \times P F S$ broth were homogenized in a small quantity of distilled water. Such cell suspensions were highly viscous. Large arrow $=$ direction of swimming; small arrow = direction of propagation of helical waves along the tail fascicle.

all flagellar fascicles and thereby improved their visibility; by this means the existence of a leading fascicle was verified. The leading fascicle was much shorter than the tailing fascicle, however, and its immaturity was probably attributable to the rapid cell division occurring in the young cultures. (ii) As the concentration of viscous agent was increased beyond its optimal level, the cells swam more slowly. With the very high concentrations $(11.0 \%, 1.5 \%$, and $4.0 \%$ for gelatin, DNA, and methylcellulose, respectively), the cells could hardly move at all. (iii) As concentrations of viscous agents were decreased below the optimal levels, the cells swam for shorter distances with frequent stopping and starting (the tailing fascicle coiled up and then extended with each stop and start [Fig. 6B]). The proportion of motile cells also decreased. With lower concentrations of agents, the frequency of stopping and starting increased until it became an almost continuous process. (iv) Without any added agents, the proportion of motile cells was at its minimum, and the type of motility occurring was quite different from the steady "straight-line" swimming or the "stop-start" swimming described above. The path of movement was usually irregular and the cells frequently moved in circles. If the motile cells were free and unattached to the glass surface of the slide, the single visible flagellar fascicle was seen to be a coiled leading fascicle (Fig. 6C). The immature fascicle at the opposite pole could not be seen except by use of polyethylene glycol, but it is possible that this fascicle may have provided most of the propulsive force under these circumstances. It is difficult to see how a coiled leading fascicle could provide such propulsion. For cells which were motile on the glass surface of the slide, a different situation occurred. The single 
visible polar fascicle was extended behind the cell and was apparently adherent to the surface. As helical waves passed from base to tip along this adherent fascicle, the cell moved along the surface (Fig 6D).

The motility-track technique was used to quantify more precisely the effect of viscosity on motility. Because of its clarity, only methylcellulose was used. Cells cultured for 8,12 , and $24 \mathrm{~h}$ were tested against various concentrations of this agent. Examples of motility-track photomicrographs for strain XI are presented in Fig. 7, and calculations based on such photographs are given in Table 2 . It can be seen that the age of the culture was important, with 8-hold cultures exhibiting the greatest proportion of motile cells. With 8-h-old cultures, although the proportion was greatest $(98 \%)$ with $1.5 \%$ methylcellulose (viscosity $=203$ centipoise [cp]), $39 \%$ of the cells were motile even in plain PFS broth (viscosity $=1.77 \mathrm{cp}$ ). The motility of cells in PFS broth was not of the straight-swimming or stop-start types, and the velocity of the cells was only half as great as it was with methylcellulose. With 12-h-old cultures, the proportion of motile cells was still very high $(96 \%)$ in $1.5 \%$ methylcellulose, but only $4 \%$ were motile in plain PFS broth. With 24-h-old cultures, only $7 \%$ of the cells were motile with $1.5 \%$ methylcellulose, and none of the cells were motile in plain PFS broth.

Similar results were obtained with motility tracks of strains X and XII; however, the optimal concentration of methylcellulose was $0.5 \%$ (viscosity $=10.14 \mathrm{cp}$ ) for these strains.

Physiological characteristics of strains $X$, XI, and XII. These strains grew most rapidly at $30 \mathrm{C}$, with no growth below $20 \mathrm{C}$ or above $40 \mathrm{C}$. Their optimal $\mathrm{pH}$ was 7.0 , with no growth occurring below 5.5 or above 8.5 . They possessed a strictly respiratory metabolism, with oxygen serving as the electron acceptor; however, growth could occur anaerobically in the presence of nitrate. Acidic reactions were not obtained with any of the 22 carbohydrates tested. Positive reactions were obtained for catalase, oxidase, and phosphatase tests. A water-soluble yellow-green fluorescent pigment could be discerned on PFS agar plates when examined by ultraviolet light $(253.7 \mathrm{~nm})$. Other characteristics are summarized in Table 3 . Nitrogenase activity was discovered late in the study and is discussed separately below. Strain XI yielded the following values for oxygen uptake (microliters of oxygen taken up per milligram [dry weight] of cells per hour at $30 \mathrm{C}$, with correction for endogenous uptake): pyruvate, 130; succinate, 127; fumarate, 118; malate, 102; valerate, 50; and lactate, 43.
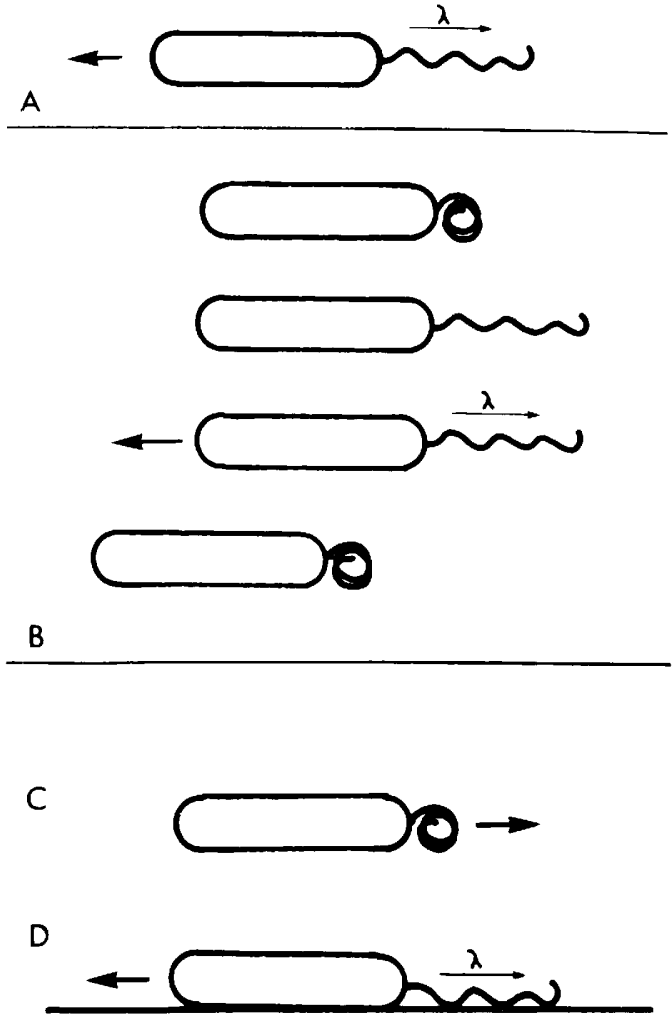

FIG. 6. Diagrammatic illustration of the orientation of the large, visible flagellar fascicle in motile cells cultured for 8 to $10 \mathrm{~h}$ in PFS broth on a shaking machine. The cells were suspended in various concentrations of viscous agents (gelatin, DNA, or methylcellulose). (A) Flagellar orientation characteristic during straight-line swimming when optimal concentrations of viscous agents were applied. (B) Flagellar orientation during stop-start swimming in the presence of decreased levels of viscous agents. (C) Flagellar orientation characteristic of cells swimming in absence of viscous agents; swimming occurred in irregular, circular paths. (D) Flagellar orientation during movement along the glass surface in absence of viscous agents; the fascicle was adherent to the surface. All cells possessed a second, immature, short flagellar fascicle at the opposite pole, which was not visible under the experimental conditions. Large arrows = direction of cell movement; small arrows $=$ direction of propagation of helical waves.

DNA base composition. Determination of the moles percent guanine plus cytosine $(\mathrm{G}+\mathrm{C})$ composition of the DNA by thermal denaturation $\left(T_{m}\right)$ methods indicated an average value of $65.0 \mathrm{~mol} \%$ for strain X, $62.0 \mathrm{~mol} \%$ for strain $\mathrm{XI}$, and 64.4 mol\% for strain XII.

Nutrition. Studies of nutritional requirements for strains X and XI were initially hampered because, although the strains grew well 

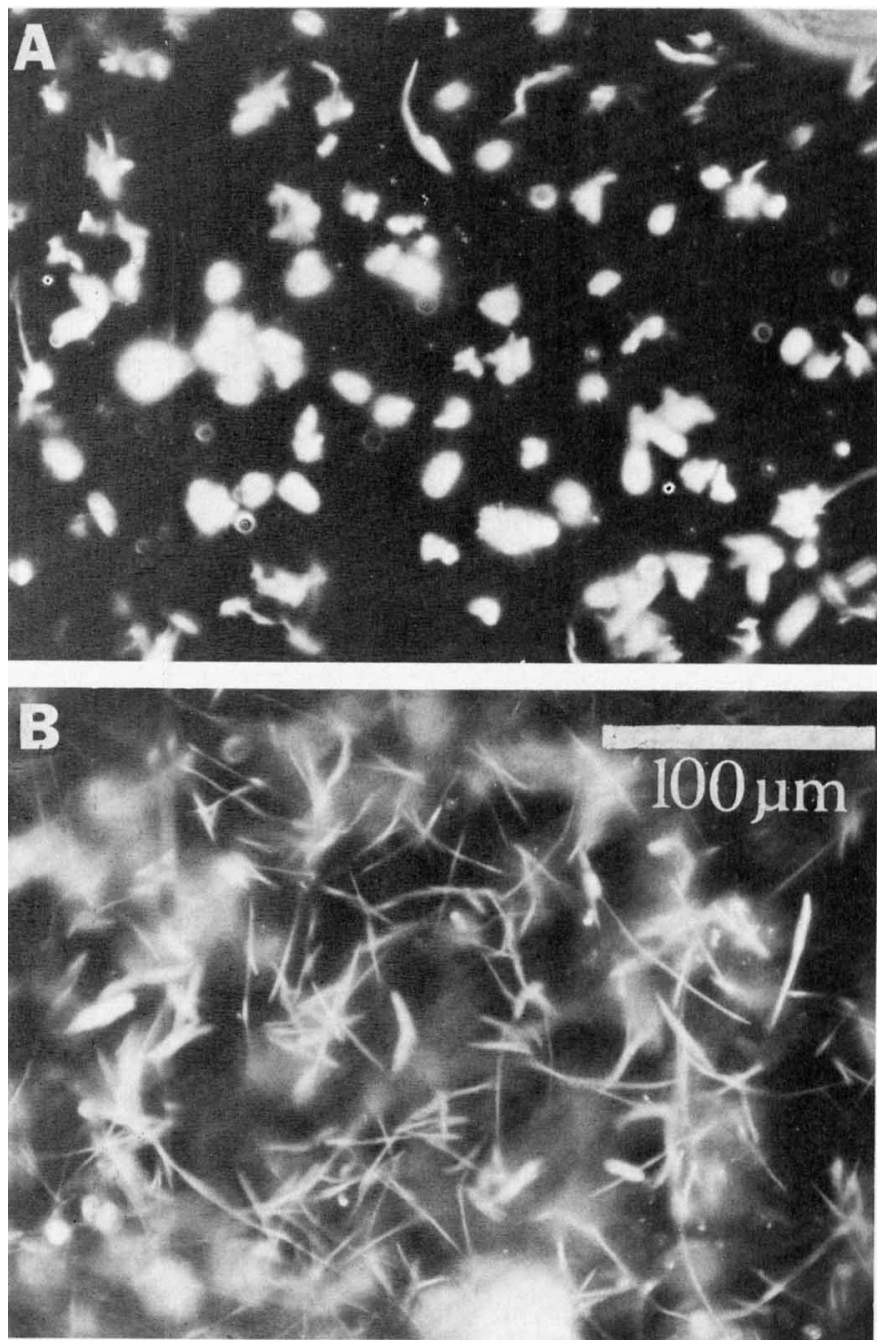

FIG. 7. Motility-track dark-field photomicrographs of cells of strain XI cultured for 12 h in PFS broth on a shaking machine. Exposure time $=15 \mathrm{~s}$. (A) Cells in plain PFS broth (viscosity $=1.77 \mathrm{cp}$ ). (B) Cells in PFS broth containing $1.5 \%$ methylcellulose (viscosity $=203 \mathrm{cp}$ ).

in PFS broth from $0.1 \mathrm{ml}$ of a 5-Klett unit, washed suspension, they rarely grew in defined liquid media containing $\left(\mathrm{NH}_{4}\right)_{2} \mathrm{SO}_{4}$, fumaric acid, and mineral salts. Heavier inocula (50 Klett units) or inocula containing nondispersed flocs of cells gave a higher frequency of growth among series of replicates but did not always insure positive results. The incorporation of $0.15 \%$ agar (even specially cleansed agar prepared by dialyzing purified agar against distilled water, followed by alcohol precipitation) invariably insured positive growth responses, however.

The necessity of supplementing defined media with agar could not be eliminated by the use of decreased oxygen levels, a variety of vitamins and coenzymes, various metal ions, ashed agar, chelating agents, various levels of carbon dioxide, or more concentrated or more dilute media. Viscous agents such as methylcellulose, polyvinylpyrrolidone, or gelatin could substitute for agar, however. Since all attempts to obtain growth consistently in defined media devoid of gels failed, $0.15 \%$ purified agar (BBL) was incorporated routinely into all media employed for determination of sole carbon and nitrogen sources. Using such semisolid media, strains $\mathrm{X}$ and XI appeared to have a simple nutrition (strain XII was not tested). The following compounds could serve as sole carbon 
TABLE 2. Relationship of viscosity to the proportion and velocity of motile cells of strain XI from motility-track photomicrographs

\begin{tabular}{|c|c|c|c|c|c|}
\hline $\begin{array}{l}\text { Age of cul- } \\
\text { ture (h) }\end{array}$ & Viscosity (cp) & $\begin{array}{c}\text { Cells motile } \\
(\%)\end{array}$ & $\begin{array}{l}\text { Avg velocity } \\
\text { of motile } \\
\text { cells }(\mu \mathrm{m} / \\
\text { min })\end{array}$ & $\begin{array}{l}\text { Highest ve- } \\
\text { locity ob- } \\
\text { served } \\
(\mu \mathrm{m} / \mathrm{min})\end{array}$ & Type of motility \\
\hline \multirow[t]{5}{*}{8} & 633 & 73 & 235 & 425 & Straight-line swimming \\
\hline & 203 & 98 & 320 & 805 & Straight-line swimming \\
\hline & 53.5 & 90 & 231 & 454 & Straight-line swimming \\
\hline & 10.14 & 72 & 193 & 427 & Beginning to stop-start \\
\hline & $1.77^{b}$ & 39 & 142 & 263 & Irregular, circular paths \\
\hline \multirow[t]{5}{*}{12} & 633 & 61 & 202 & 555 & Straight-line swimming \\
\hline & 203 & 96 & 186 & 360 & Straight-line swimming \\
\hline & 53.5 & 84 & 141 & 245 & Straight-line swimming \\
\hline & 10.14 & 34 & 126 & 187 & Beginning to stop-start \\
\hline & 1.77 & 4 & 98 & 143 & Irregular, circular paths \\
\hline \multirow[t]{5}{*}{24} & 633 & 4 & 169 & 189 & Straight-line swimming \\
\hline & 203 & 7 & 173 & 292 & Straight-line swimming \\
\hline & 53.5 & 5 & 182 & 292 & Straight-line swimming \\
\hline & 10.14 & 5 & 172 & 214 & Beginning to stop-start \\
\hline & 1.77 & 0 & & & None \\
\hline
\end{tabular}

${ }^{a}$ See Fig. 6. Straight-line swimming = Fig. 6A. Stop-start swimming = Fig. 6B. Irregular, circular paths $=$ Fig. $6 \mathrm{C}$ and $6 \mathrm{D}$.

${ }^{b}$ No methylcellulose added; cells in plain PFS broth.

TABLE 3. Physiologic characteristics of strains $X, X I$, and $X I I$

\begin{tabular}{|c|c|c|}
\hline Test & $\begin{array}{l}\text { Age of culture } \\
\text { (days) }\end{array}$ & Reaction \\
\hline $\mathrm{H}_{2} \mathrm{~S}$ from $0.2 \%$ cysteine or thiosulfate ${ }^{a}$ & 7 & - to trace \\
\hline Nitrate reduced to nitrite ${ }^{a}$ & 7 & + \\
\hline Growth in presence of $3 \%$ bile $^{a}$ & 14 & + \\
\hline Growth in presence of $1 \%$ glycine ${ }^{a}$ & 14 & - \\
\hline Hydrolysis of esculin or hippurate $e^{a}$ & 4 & - \\
\hline Liquefaction of $12 \%$ gelatin ${ }^{\prime \prime}$ & 4 & - \\
\hline Hydrolysis of casein, starch, or tributyrin ${ }^{c}$ & 14 & - \\
\hline Growth in presence of $0.8 \% \mathrm{NaCl}^{a}$ & 14 & + \\
\hline Growth in presence of $1.0 \% \mathrm{NaCl}^{\prime \prime}$ & 14 & - \\
\hline Oxidase $^{a}$ & 2 & + \\
\hline Catalase $^{d}$ & 1 & + \\
\hline Phosphatase ${ }^{c}$ & 4 & + \\
\hline Anaerobic growth with presence of $0.1 \% \mathrm{KNO}_{3}$ & 7 & + \\
\hline Indole $^{a}$ & 2 & - \\
\hline Urease $^{e}$ & 1 & + \\
\hline Optimum temperature for growth in semisolid PFS medium & 7 & $\begin{array}{l}30 \mathrm{C} \text {; no growth at } 20 \mathrm{C} \text { or } \\
40 \mathrm{C}\end{array}$ \\
\hline Optimum pH for growth in semisolid PFS medium & 7 & $\begin{array}{r}\text { pH } 7.0 ; \text { no growth below } \\
\text { pH } 5.5 \text { or above pH } 8.5\end{array}$ \\
\hline Acidic reactions from carbohydrates ${ }^{f}$ & 7 & - \\
\hline $\begin{array}{l}\text { Water-soluble yellow-green fluorescent pigment on PFS agar } \\
\text { (tested with a } 253.7-\mathrm{nm} \text { ultraviolet light source) }\end{array}$ & 3 & Weak + \\
\hline $\begin{array}{l}\text { Zones of inhibition around disks impregnated with: chloram- } \\
\text { phenicol, } 10 \mu \mathrm{g} \text {; penicillin, } 5 \mathrm{IU} \text {; novobiocin, } 10 \mu \mathrm{g} \text {; tetracy- } \\
\text { cline, } 10 \mu \mathrm{g} \text {; or streptomycin, } 5 \mu \mathrm{g}\end{array}$ & 1 & + \\
\hline
\end{tabular}

" PFS semisolid medium supplemented with substrate.

${ }^{b}$ PFS broth supplemented with substrate.

c PFS agar supplemented with substrate; culture applied as a streak.

${ }^{d}$ PFS agar slant.

- Cells suspended in distilled water to a dense, milky concentration; $0.5 \mathrm{ml}$ of suspension added to $2.0 \mathrm{ml}$ of the following medium: $N, N$-bis-(2-hydroxyethyl)2-aminoethane sulfonic acid, $0.005 \%$; urea, $2.0 \%$; phenol red, $0.001 \% ; \mathrm{pH} 7.0$. Controls lacking urea were used.

${ }^{f}$ Basal medium = PFS semisolid medium lacking fumaric acid with peptone decreased to $0.2 \% ; 0.003 \%$ bromothymol blue indicator added. Carbohydrates were added to a final concentration of $1.0 \%$. 
sources: fumarate, succinate, oxaloacetate, malate, pyruvate, lactate, valerate, $\beta$-hydroxybutyrate, L-alanine, L-glutamate, L-aspartate, L-glutamine, L-asparagine, L-proline, and L-arginine. Pyruvate and proline were the most effective. Compounds which could not serve as sole carbon sources were: $\alpha$-ketoglutarate, citrate, malonate, acetate, propionate, butyrate, $\beta$-hydroxybenzoate, aliphatic alcohols (C1 through C4), glycine, L-leucine, L-isoleucine, Lserine, L-threonine, L-hydroxyproline, L-ornithine, L-lysine, L-valine, L-methionine, L-cystine, L-histidine, L-tryptophan, L-tryosine, and L-phenylalanine. Moreover, none of the following carbohydrates could serve as sole carbon sources: D-glucose, D-galactose, D-xylose, D-fructose, L-sorbose, D-mannose, L-rhamnose, D-ribose, sorbitol, adonitol, erythritol, inositol, dulcitol, mannitol, glycerol, sucrose, lactose, trehalose, maltose, raffinose, cellobiose, inulin, and gluconate. Sole nitrogen sources included nitrate, ammonium ions, and 10 amino acids, with L-proline and L-alanine being the most effective. Seven amino acids could serve as sole sources of both carbon and nitrogen: L-alanine, L-proline, L-asparagine, L-arginine, L-glutamate, L-aspartate, and L-glutamine. Alanine and proline were the most effective. The use of proline for the isolation of strain XII and other strains has been mentioned.

Nitrogenase activity. When cultured in semisolid test medium lacking $\left(\mathrm{NH}_{4}\right)_{2} \mathrm{SO}_{4}$, 3day-old cultures of strains X, XI, and XII exhibited the following nitrogenase activities (nanomoles of ethylene produced per hour per culture; average of duplicate tubes), respectively: 183,194 , and 166 . For 5-day-old cultures, the values were: 84,54 , and 215 . Cultures inoculated into semisolid medium $+\left(\mathrm{NH}_{4}\right)_{2} \mathrm{SO}_{4}$ or into liquid medium with and without $\left(\mathrm{NH}_{4}\right)_{2} \mathrm{SO}_{4}$ exhibited activities of less than 0.9 nmol of ethylene. A number of species of Aquaspirillum were also tested for nitrogenase activity, and $A$. peregrinum was found to exhibit an activity of $124 \mathrm{nmol}$ of ethylene per $\mathrm{h}$ per culture at 3 days, and $103 \mathrm{nmol}$ at 5 days, in semisolid test medium without $\left(\mathrm{NH}_{4}\right)_{2} \mathrm{SO}_{4}$. Less than $0.9 \mathrm{nmol}$ of ethylene could be detected in liquid media or in media containing $\left(\mathrm{NH}_{4}\right)_{2} \mathrm{SO}_{4}$.

In semisolid test medium, strains $\mathrm{X}, \mathrm{XI}$, and XII initiated growth as a thin band or pellicle several millimeters below the surface (Fig. 8). As growth increased, the pellicle eventually moved quite close to the surface. This behavior resembled that reported by von Bülow and Döbereiner (33) for "Spirillum" lipoferum.

\section{DISCUSSION}

The development of a reliable method for the

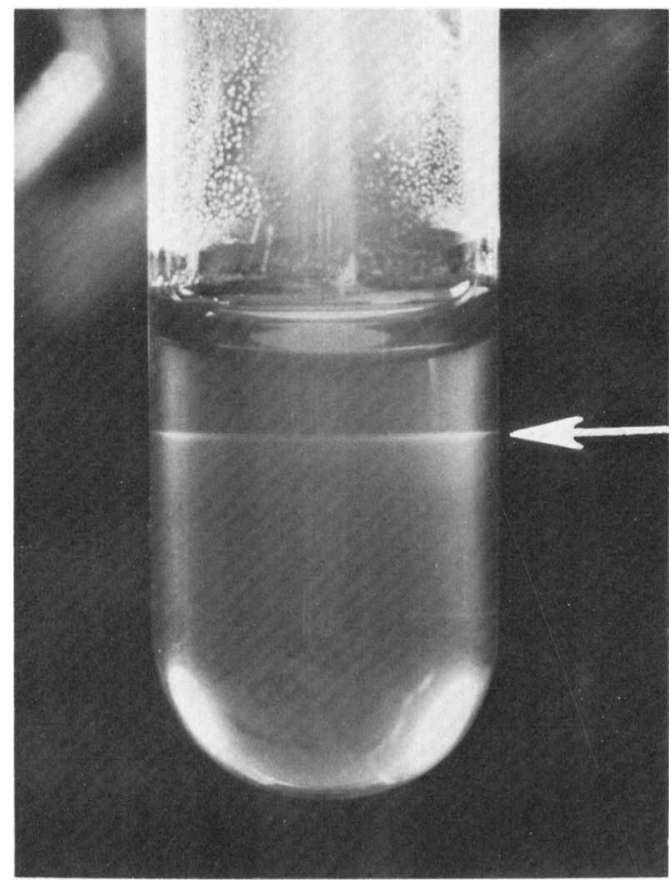

Fig. 8. Initiation of growth of strain $X$ as a microaerophilic band or pellicle (arrow) below the surface of semisolid nitrogen-limiting medium. As growth increases, the pellicle becomes denser and moves closer to the surface of the medium.

isolation of these unusual bacteria should be of interest not only to those studying the in vivo behavior of bacterial flagella but also to freshwater microbial ecologists. The isolation in Iowa and Virginia of strains having similar characteristics together with the observation of morphologically similar organisms in Germany (13) and Holland (11) suggest that this organism may have widespread distribution.

Our previous report (30), indicating an inability of free cells of this organism to swim about, is related to the present finding that the age of the cultures is important when looking for motility. For cultures in the flocculent condition, only those incubated for at least 48 to 72 $\mathrm{h}$ have revealed flocs containing motile cells. The medium is also important, with $0.1 \times$ PFS broth being the most favorable for motility within flocs. For homogeneous, turbid cultures, only young (8-h-old) cultures were found to contain many motile cells in the absence of viscous agents, and the movement of these cells was in irregular, circular paths. Moreover, their maximal velocity was 5 to 13 times slower compared to other motile bacteria (26). Schneider and Doetsch (26) found that an increase of viscosity up to 2 or $3 \mathrm{cp}$ would cause 1.1 - to 1.9 -fold increase in velocity with various species, with 
further increase in viscosity causing sharp decreases. In contrast, a viscosity of $203 \mathrm{cp}$ permitted maximal velocity of our strain XI, a velocity still much lower than that of the organisms tested by Schneider and Doetsch at 2 to 3 cp.

Schneider and Doetsch (26) provided evidence, using Thiospirillum jenense, that the viscosity of a suspending medium will control the conformation of the flagellar helix, an increase in viscosity causing a decrease in helix diameter and an increase in swimming velocity with viscosities up to 2 or $3 \mathrm{cp}$. We were not able to detect any visible change in helix diameter with our organisms even at the higher viscosities, but another change was evident. At high viscosities, the flagellar fascicles were invariably extended, whereas at lower viscosities the fascicles tended to retract and extend with higher frequency, resulting in a stop-start type of swimming. In the absence of a viscous agent, the fascicles remained retracted for the most part, except where they were adherent to the glass surface. Consequently, one effect of viscosity appears to be that of causing and maintaining an extended condition for the fascicles, necessary for steady, straight-line swimming. This suggests that, if the cells were able to maintain their fascicles in an extended condition in the absence of viscous agents, they might be able to swim quite rapidly; yet, in flocculent cultures, free cells external to the flocs or at the edges of flocs frequently exhibited extension of a fascicle (the opposite one being retracted) and generation of helical waves without any resultant swimming. This situation was also described by Strength and Krieg (30), who used only flocculent cultures. Such free cells were not in a viscous environment, since the flocs and not the medium contain the naturally occurring viscous matrix. Thus, the reasons for the effect of high viscosity on the motility of our organisms are not clear. Another phenomenon difficult to explain is the irregular, circular-path type of motility occurring in cells from homogeneous cultures in plain PFS broth. As indicated in Fig. 6C, young cells possess only one visible fascicle: this is the tailing fascicle in viscous solutions, but in plain PFS broth it is a retracted, coiled leading fascicle. It is difficult to understand how the cells could move forward with such a fascicular configuration; however, the short, immature fascicle at the opposite pole, whose orientation cannot be seen, may play the major role in this type of motility.

On initial isolation, the organisms are invariably highly flocculent, and it is clear that the cells are well adapted to this situation in terms of their motility. The ability of cells to swim in straight lines in highly viscous solutions, the steady straight-line swimming observed in free cells prepared by thorough homogenization of flocs in a small amount of water, and the observed straight-line motility within cell flocs all support the concept of a specialized type of motility. Since diffusion of oxygen and nutrients must be limiting factors for the growth of aerobic cells within a floc, the ability of cells to move through the viscous matrix to the edges of the floc would seem to be quite advantageous. Although the organisms might be considered to be mutants defective for normal motility, the above considerations as well as the wide geographical distribution of such organisms suggest an adaptation for a specific environment rather than a defect.

With regard to nitrogenase activity, it is significant that strains $\mathrm{X}, \mathrm{XI}$, and XII initiated growth in semisolid test medium several millimeters below the surface. A similar situation was reported by von Bülow and Döbereiner (33) with "Spirillum" lipoferum, and presumably this microaerophilic pellicle represents growth at a location where there is sufficient oxygen for respiration but not enough to inhibit nitrogenase. The ability to demonstrate nitrogenase activity in strains X, XI, and XII only in semisolid medium, not liquid medium, supports this hypothesis. Recently, Kurz and LaRue (18) noted that, with pure cultures of rhizobia, acetylene reduction was observed only with strains which produced copious amounts of slime. They suggested that this serves to protect the nitrogenase from oxygen. In the present study, nitrogenase activity was tested only with cultures which had lost their initial floc-forming ability. It is quite possible that, just as semisolid agar permitted nitrogenase activity with these cultures, the viscosity of the flocs characteristically formed by strains X, XI, and XII on initial isolation might exert a similar protective effect, making semisolid agar unnecessary for demonstration of nitrogenase activity with fresh isolates. This hypothesis has not yet been tested.

Concerning the taxonomy of the organisms, certain difficulties are evident from a consideration of the morphological and physiological characters. Several characters suggest a relationship to the genus Pseudomonas: Gram reaction, rod shape, possession of a strictly respiratory rather than fermentative type of metabolism, formation of a fluorescent pigment (although weakly), lack of sheaths or prosthecae, and a DNA base composition of 62 to $65 \mathrm{~mol} \%$ $\mathrm{G}+\mathrm{C}$. The flocculent nature of the organisms is also suggestive of Zoogloea (6), but, unlike zoogloeae, they do not attack carbohydrates, 
they possess multiple flagella, and they do not form finger-like or dendritic outgrowths on flocs.

Several lines of evidence suggest that, despite their rod shape, the organisms are closely related to members of the genus Aquaspirillum (freshwater chemoheterotrophic aerobic spirilla [12]) and are essentially nonhelical spirilla. (i) The possession of large bipolar fascicles of flagella is typical of most members of Aquaspirillum. (ii) The $\mathrm{G}+\mathrm{C}$ value of 62 to $65 \mathrm{~mol} \%$ is consistent with that of Aquaspirillum (50 to $65 \mathrm{~mol} \%$ ). (iii) The occurrence of a polar membrane (Fig. 3) has been associated mainly with helical bacteria $(9,10,16,20,24)$. (iv) Coccoid body formation occurs in several species of $A q$ uaspirillum (A. itersonii, A. peregrinum, and A. polymorphum) as well as in other helical bacteria, such as members of Oceanospirillum (12), Campylobacter (21, 28), and Vibrio (2, 27). (v) Some species of Aquaspirillum become nearly straight rods upon prolonged transfer or by selection of mutants $(31,34$; see also Fig. 16 and 19 in reference 12 ). (vi) A strain recently isolated in our laboratory, at first identical in morphology to strains X, XI, and XII, now exhibits many cells which are curved or even Sshaped after prolonged serial transfer. (vii) The possession of a strictly respiratory type of metabolism, the inability to catabolize carbohydrates, the positive reactions obtained for the catalase, oxidase, and phosphatase tests, the inability to attack gelatin, esculin, hippurate, casein, or starch, the failure to form indole, the lack of tolerance to $\mathrm{NaCl}$ or glycine, and the presence of intracellular poly- $\beta$-hydroxybutyrate granules, are all typical of members of $A q-$ uaspirillum.

The nitrogenase activity and polar flagellation exhibited by strains X, XI, and XII suggest a relationship to Azomonas insignis and to Azomonas macrocytogenes (14). The slime production especially suggests the latter organism. However, electron micrographs showing the morphology and flagellation of cells of the two species (1) indicate organisms which are quite different from strains X, XI, and XII. Furthermore, the two species have DNA base compositions of 57 to $59 \mathrm{~mol} \% \mathrm{G}+\mathrm{C}$, in contrast to 62 to 65 mol\% for strains X, XI, and XII.

The occurrence of nitrogen-fixing spirilla was reported by Beijerinck $(4,5)$ in 1922 and 1925 . Dalton (7) has noted that a number of aerobic spirilla reputed to fix nitrogen have been isolated by Russian investigators. In 1963, Becking (3) isolated an organism which he considered to be identical to Beijerinck's Spirillum lipoferum and which assimilated ${ }^{15} \mathrm{~N}_{2}$. At the
1974 International Symposium on Nitrogen Fixation (Washington State University, June 1974), Döbereiner and Day reported that root pieces from tropical grasses exhibited nitrogenase activity. From the roots, they isolated organisms which greatly resembled Beijerinck's $S$. lipoferum. Successful isolation depended on the use of a semisolid nitrogen-free medium, in which the spirilla grew several millimeters below the surface at a location where the dissolved oxygen concentration was sufficient for respiration without inhibiting the nitrogenase (33). The pellicle so formed eventually moved closer to the surface as growth increased. von Bülow and Döbereiner (33) have also isolated $S$. lipoferum from the roots of maize. The occurrence of such nitrogen-fixing spirilla led us to apply the use of semisolid media to strains $\mathrm{X}$, XI, and XII, with the subsequent demonstration of nitrogenase activity. The question of the relationship of these strains to members of the genus Aquaspirillum prompted us to examine the ability of a number of Aquaspirillum species to exhibit nitrogenase activity, and $A$. peregrinum was found to be active. Consequently, we believe that nitrogenase activity of strains $\mathrm{X}, \mathrm{XI}$, and XII offers no obstacle to the inclusion of these strains in the genus Aquaspirillum. Also, to exclude the organisms from this genus merely because of their rod shape, a single and probably mutable characteristic, does not appear to be reasonable. Therefore, we propose that strains X, XI, and XII be included in Aquaspirillum in a new species, Aquaspirillum fasciculus.

Aquaspirillum fasciculus sp. nov. (fas.ci'.cu.lus. L.mas. dim.noun fasciculus a small bundle.)

Description of species. Gram-negative rods, 0.7 to $0.9 \mu \mathrm{m}$ in diameter (mean values) by phase-contrast microscopy. Strain XII has a mean cell diameter slightly larger than that of strains $\mathrm{X}$ and XI $(0.88 \mu \mathrm{m}$ compared to 0.76 $\mu \mathrm{m})$. Length: approximately 5 to $10 \mu \mathrm{m}$, but old cultures may contain cells up to $42 \mu \mathrm{m}$ in length. Possess flagella in bipolar fascicles which are easily seen by dark-field or phasecontrast microscopy and which exhibit an extended form with helical wave propagation; the fascicles retract by coiling into a polar loop or by bending at the base, frequently with coiling around the cell. Cells contain prominent poly$\beta$-hydroxybutyrate granules. All strains grow well in PFS broth, but strain XII grows more slowly than the others. Growth occurs in viscous flocs upon initial isolation; this property may be lost upon continued transfer. Cells move in straight lines within the flocs, espe- 
cially when cultured in $0.1 \times$ PFS broth. Cells at the periphery of the flocs, and free cells, move in irregular, circular paths if motile at all. Cells from homogeneous cultures swim best in highly viscous media. The optimal viscosity of methyl-cellulose " $400 \mathrm{cp}$ " for the motility of strain XI is approximately $200 \mathrm{cp}$, whereas that for strains X and XII is approximately $10 \mathrm{cp}$. Maximal motility is exhibited by cells cultured for $8 \mathrm{~h}$ in PFS broth prior to being suspended in methylcellulose medium. Coccoid bodies predominate in old (48- to 72-h-old) cultures, and were chemo-organotrophic, having a strictly respiratory metabolism with oxygen as the terminal electron acceptor. Growth occurs anaerobically with nitrate. Nitrates are reduced to nitrites. Nitrogenase activity is present. Catalase, oxidase, phosphatase, and urease are produced. Growth does not occur in the presence of $1 \%$ glycine or $1 \% \mathrm{NaCl}$. Indole is not produced. Gelatin is not liquefied. Esculin, hippurate, tributyrin, casein, and starch are not hydrolyzed. Carbohydrates are not catabolized. Growth occurs best in defined media when $0.15 \%$ agar is added. Although the nutrition of strain XII has not yet been studied, strains $\mathrm{X}$ and $\mathrm{XI}$ can use several tricarboxylic acid cycle intermediates (but not citrate or $\alpha$ ketoglutarate), valerate, $\beta$-hydroxybutyrate, and several amino acids as sole carbon sources when $\left(\mathrm{NH}_{4}\right)_{2} \mathrm{SO}_{4}$ is the nitrogen source supplied. Nitrate, ammonium ions, and several amino acids can be used as sole nitrogen sources when fumarate is the carbon source. Proline can be used as a source of both carbon and nitrogen. The $\mathrm{G}+\mathrm{C}$ content of the DNA is $65.0 \mathrm{~mol} \%$ for strain X, $62.0 \mathrm{~mol} \%$ for strain XI, and $64.4 \mathrm{~mol} \%$ for strain XII. Habitat: pond water.

Type strain. We designate strain XI as the type strain of the species. This strain has been deposited with the American Type Culture Collection under the number 27740. Strains $\mathrm{X}$ and XII have been deposited as reference strains under the numbers ATCC 29048 and ATCC 29049 , respectively. All of the strains possess the characteristics indicated for the species.

\section{ACKNOWLEDGMENTS}

We thank R. G. E. Murray, Department of Bacteriology, University of Western Ontario, London, Ontario, Canada, for suggestions concerning the classification of the organisms. We are also grateful to John L. Johnson, Anaerobe Laboratory, Virginia Polytechnic Institute and State University, Blacksburg, Va., for his help in the determination of DNA base compositions.

\section{REPRINT REQUESTS}

Address reprint requests to: Dr. Noel R. Krieg, Biology Department, Virginia Polytechnic Institute and State University, Blacksburg, Va. 24061.

\section{LITERATURE CITED}

1. Baillie, A., W. Hodgkiss, and J. R. Norris. 1962. Flagellation of Azotobacter as demonstrated by electron microscopy. J. Appl. Bacteriol. 25:116-119.

2. Baker, D. A., and R. W. A. Park. 1975. Changes in morphology and cell wall structure that occur during growth of Vibrio sp. NCTC 4716 in batch culture. J. Gen. Microbiol. 86:12-28.

3. Becking, J. H. 1963. Fixation of molecular nitrogen by an aerobic Vibrio or Spirillum. Antonie van Leeuwenhoek J. Microbiol. Serol. 29:326.

4. Beijerinck, M. W. 1922. Azotobacter chroococcum als indikator van de vruchtbaarheid van den grond. K. Ned. Akad. Wet., Versl. Gewone Vergad. Afd. Natwurkd. 30:431-438.

5. Beijerinck, M. W. 1925. Uber ein Spirillum, welches freien Stickstoff binden kann? Zentralbl. Bakteriol. Parasitenk. Infektionskr. Abt. II 63:353-359.

6. Crabtree, K., and E. McCoy. 1974. Genus Zoogloea, p. 249-250. In R. E. Buchanan and N. E. Gibbons (ed.)., Bergey's manual of determinative bacteriology, 8th ed. The Williams and Wilkins Co., Baltimore.

7. Dalton, H. 1974. Fixation of dinitrogen by free-living microorganisms. CRC Crit. Rev. Microbiol. 3:183220 .

8. Friedman, B. A., P. R. Dugan, R. M. Pfister, and C. C. Remsen. 1969. Structure of exocellular polymers and their relationship to bacterial flocculation. J. Bacteriol. 98:1328-1344.

9. Hickman, D. I., and A. W. Frenkel. 1965. Observations on the structure of Rhodospirillum molischianum. J. Cell Biol. 25:261-278.

10. Hickman, D. D., and A. W. Frenkel. 1965. Observations on the structure of Rhodospirillum rubrum. J. Cell Biol. 25:279-291.

11. Houwink, A. L. 1953. A macromolecular mono-layer in the cell wall of Spirillum spec. Biochim. Biophys. Acta 10:360-366.

12. Hylemon, P. B., J. S. Wells, Jr., N. R. Krieg, and H. W. Jannasch. 1973. The genus Spirillum: a taxonomic study. Int. J. Syst. Bacteriol. 23:340-380.

13. Jarosch, R. 1969. Lebenbeobachtungen an Bakteriengeisseln und ihre mögliche Bedeutung für die Interpretation der Dynamik endoplasmatischer Fibrillen. Mikroskopie 25:186-196.

14. Johnstone, D. B. 1974. Genus Azomonas, p. 255-256. In R. E. Buchanan and N. E. Gibbons (ed.), Bergey's manual of determinative bacteriology, 8th ed. The Williams and Wilkins Co., Baltimore.

15. Kay, D. H. 1965. Techniques for electron microscopy, 2nd ed., p. 176. F. A. Davis Co., Philadelphia.

16. Keeler, R. F., A. E. Ritchie, J. H. Bryner, and Jane Elmore. 1966. The preparation and characterization of cell walls and the preparation of flagella of Vibrio fetus. J. Gen. Microbiol. 43:439-462.

17. Kellenberger, E., A. Ryter, and J. Sechaud. 1958. Electron microscope study of DNA-containing plasma. II. Vegetative and mature phase DNA as compared with normal bacterial nucleoids in different physiological states. J. Biophys. Biochem. Cytol. 4:671-676.

18. Kurz, W. G. W., and T. A. LaRue. 1975. Nitrogenase activity in rhizobia in absence of plant host. Nature (London) 256:407-409.

19. Law, J. H., and R. A. Slepecky. 1961. Assay of poly- $\beta$ hydroxybutyric acid. J. Bacteriol. 82:33-36.

20. Murray, R. G. E., and A. Birch-Andersen. 1963. Specialized structure in the region of the flagella tuft in Spirillum serpens. Can. J. Microbiol. 9:393-401.

21. Ogg, J. E. 1962. Studies on the coccoid form of ovine Vibrio fetus. I. Cultural and serologic investigations. Am. J. Vet. Res. 23:354-358.

22. Postgate, J. R. 1972. The acetylene reduction test for 
nitrogen fixation, p. 343-356. In J. R. Norris and D. W. Ribbins (ed.), Methods in microbiology, vol. 6B. Academic Press Inc., New York.

23. Reynolds, E. S. 1963 . The use of lead citrate at high $\mathrm{pH}$ as an electron opaque stain in electron microscopy. J. Cell Biol. 17:208-212

24. Ritchie, A. E., R. F. Keeler, and J. H. Bryner. 1966. Anatomical features of Vibrio fetus: electron microscope survey. J. Gen. Microbiol. 43:427-438.

25. Rittenberg, B. T., and S. C. Rittenberg. 1962. The growth of Spirillum volutans Ehrenberg in mixed and pure cultures. Arch. Mikrobiol, 43:138-153.

26. Schneider, W. R., and R. N. Doetsch. 1974. Effect of viscosity on bacterial motility. J. Bacteriol. 117:696701 .

27. Shewan, J. M., and M. Véron. 1974. Genus Vibrio, p. 340-345. In R. E. Buchanan and N. E. Gibbons (ed.), Bergey's manual of determinative bacteriology, 8th ed. The Williams and Wilkins Co., Baltimore.

28. Smibert, R. M. 1974. Genus Campylobacter, p. 207-212. In R. E. Buchanan and N. E. Gibbons (ed.), Bergey's manual of determinative bacteriology, 8th ed. The Williams and Wilkins Co., Baltimore.

29. Stempak, J. G., and R. T. Ward. 1964. An improved staining method for electron microscopy. J. Cell Biol. 22:679-701

30. Strength, W. J., and N. R. Krieg. 1971. Flagellar activity in an aquatic bacterium. Can. J. Microbiol. 17:1133-1137.

31. Terasaki, Y. 1972. Studies on the genus Spirillum Ehrenberg. I. Morphological, physiological, and biochemical characteristics of water spirilla. Bull. Suzugamine Women's Coll. Nat. Sci. 16:1-146.

32. Vaituzis, A., and R. N. Doetsch. 1969. Motility tracks: technique for quantitative study of bacterial movement. Appl. Microbiol. 17:584-588.

33. von Bülow, J. F. W., and J. Döbereiner. 1975. Potential for nitrogen fixation in maize genotypes in Brazil. Proc. Natl. Acad. Sci. U. S. A. 72:2389-2393.

34. Williams, M. A. 1959. Some problems in the identification and classification of Spirillum. Int. Bull. Bacteriol. Nomencl. Taxon. 9:35-55. 